This item was submitted to Loughborough's Research Repository by the author.

Items in Figshare are protected by copyright, with all rights reserved, unless otherwise indicated.

\title{
The effects of fuel dilution in a natural-gas direct-injection engine
}

PLEASE CITE THE PUBLISHED VERSION

PUBLISHER

Professional Engineering Publishing / @ IMECHE

VERSION

VoR (Version of Record)

LICENCE

CC BY-NC-ND 4.0

REPOSITORY RECORD

McTaggart-Cowan, G.P., S.N. Rogak, P.G. Hill, S.R. Munshi, and W.K. Bushe. 2019. "The Effects of Fuel Dilution in a Natural-gas Direct-injection Engine”. figshare. https://hdl.handle.net/2134/5017. 
This item was submitted to Loughborough's Institutional Repository (https://dspace.lboro.ac.uk/) by the author and is made available under the following Creative Commons Licence conditions.

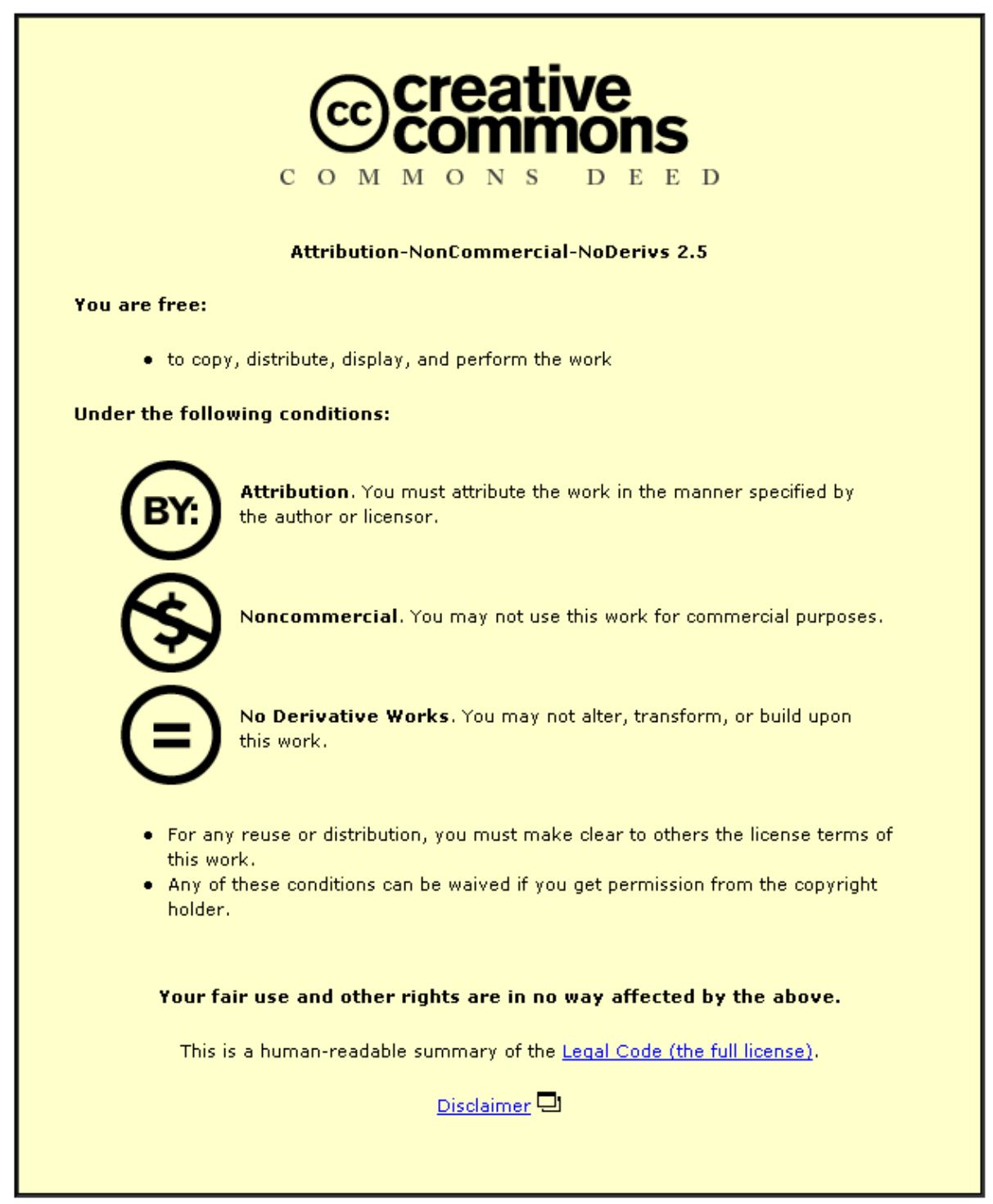

For the full text of this licence, please go to: http://creativecommons.org/licenses/by-nc-nd/2.5/ 


\title{
The effects of fuel dilution in a natural-gas direct-injection engine
}

G P McTaggart-Cowan ${ }^{1 *}$, S N Rogak ${ }^{2}$, P G Hill ${ }^{2}$, S R Munshi ${ }^{3}$, and W K Bushe ${ }^{2}$

Wolfson School of Mechanical \& Manufacturing Engineering, Loughborough University, Loughborough, UK

Department of Mechanical Engineering, University of British Columbia, Vancouver, Canada

Westport Power Inc., Vancouver, Canada

The manuscript was received on 28 August 2007 and was accepted after revision for publication on 4 December 2007.

DOI: 10.1243/09544070JAUTO705

\begin{abstract}
This study reports the effects of fuelling a heavy-duty single-cylinder research engine with pilot-ignited late-cycle direct-injected natural gas diluted with 0, 20, and 40 per cent nitrogen. The combustion duration is unaffected while its intensity is reduced and its stability is increased. Emissions of nitrogen oxides, particulate matter, hydrocarbons, and carbon monoxide are all reduced, with no effect on the engine's performance and efficiency. The results indicate the benefits of increased in-cylinder turbulence and are of particular relevance when considering fuel composition variations with non-conventional sources of gaseous fuels.
\end{abstract}

Keywords: fuel dilution, direct injection, natural gas engine

\section{INTRODUCTION}

Heavy-duty engine manufacturers are developing advanced in-cylinder and post-exhaust systems to ensure that diesel engines meet stringent new emission standards. One technique to reduce engine-out emissions of local and global air pollutants is to replace the diesel fuel with natural gas. A barrier to using natural gas is that its composition can vary significantly between suppliers, seasons, and geographical sources. The addition of unconventional and bio-derived gases to fossil natural gas can have an even greater effect on fuel composition [1]. These constituents can include heavier hydrocarbons (HCs) or inert diluents. The presence of diluents, such as molecular nitrogen $\left(\mathrm{N}_{2}\right)$, can significantly influence the combustion and emissions. Varying the fuel composition can also provide insight into the fundamental combustion factors that influence pollutant formation. This study investigates the impacts of diluting natural gas with various levels of $\mathrm{N}_{2}$ on the combustion and emis-

${ }^{*}$ Corresponding author: Wolfson School of Mechanical \& Manufacturing Engng, Loughborough University, Loughborough, Leicestershire, LE11 3TU, UK. email: g.mctaggart-cowan@lboro. ac.uk sions of a heavy-duty compression ignition directinjection engine.

\subsection{Combustion system}

One technology for natural gas fuelling of heavyduty engines, developed by Westport Power Inc., uses natural gas injected directly into the combustion chamber late in the compression stroke. This technology retains the performance and efficiency of an equivalently sized diesel engine [2]. As the pressure and temperature in the combustion chamber are not sufficient for natural gas to autoignite reliably, a small amount of diesel fuel is injected prior to the natural gas. The autoignition and combustion of this pilot fuel provides the ignition source for the gaseous fuel, which then burns in a predominantly non-premixed combustion event. The corresponding heat release rate (HRR) is similar to that for conventional diesel fuelling. Compared with diesel fuelling, carbon dioxide $\left(\mathrm{CO}_{2}\right)$ emissions are reduced by the lower carbon to energy ratio of the natural gas, while its lower adiabatic flame temperature significantly reduces emissions of nitrogen oxides $\left(\mathrm{NO}_{x}\right)$ and its lower sooting tendency reduces fine particulate matter (PM) emissions. 
Test-cycle engine emissions have been certified at levels lower than the 2006 requirements of the US Environmental Protection Agency [3]. Further, as the natural gas is not premixed in the combustion chamber, emissions of unburned fuel are significantly lower than from many other natural gas fuelling technologies [4].

Using exhaust gas recirculation (EGR) can achieve substantial further reductions in $\mathrm{NO}_{x}$ emissions; however, the combustion is degraded and emissions of unburned fuel, carbon monoxide (CO), and PM are excessive [5]. At high EGR levels, more than 90 per cent of the PM originates from the natural gas [6]. The combustion event is also influenced by the longer ignition delays and slower combustion rates associated with high-EGR operation in non-premixed combustion systems [7]. As the timing of the injection process is essentially independent of the level of EGR in the charge, longer ignition delays with EGR result in a greater partially premixed combustion event, and a corresponding reduction in the non-premixed combustion phase. This can lead to combustion which appears similar to the partially premixed compression ignition or controlled auto-ignition technologies under development for diesel engines $[\mathbf{8}, \mathbf{9}]$. In these technologies, high EGR rates are typically combined with advanced injections to provide near-homogeneous autoignition combustion, resulting in a significant reduction in $\mathrm{PM}$ and $\mathrm{NO}_{x}$ formation by substantially reducing the combustion temperature $[\mathbf{8}, \mathbf{1 0}]$. In this work, the combustion system investigated remains a late-cycle injection process, with the diesel pilot preceding the main natural-gas injection. The effects of diluting the fuel with an inert species have not been investigated previously; it is expected that they will differ significantly from the effects of charge dilution through the use of EGR.

\subsection{Fuel dilution}

The effect of diluting a gaseous fuel with nitrogen has been investigated in various contexts. In automotive premixed-charge spark ignition engines, $\mathrm{NO}_{x}$ emissions and pre-ignition knock can be reduced through the addition of $\mathrm{N}_{2}$ to both gaseous and liquid fuels $[11,12]$. For the same total fuel energy content in a premixed-charge system, diluting the fuel has essentially the same effect as diluting the oxidizer.

For non-premixed combustion, the effects of fuel dilution may vary substantially from those of oxidizer dilution. Oxidizer dilution with $\mathrm{N}_{2}$ behaves very similarly to conventional EGR, reducing NO formation by reducing flame temperatures [7]. In industrial boilers (low-pressure non-premixed turbulent combustion), fuel dilution reduces $\mathrm{NO}_{x}$ more effectively than does oxidizer dilution [13]. This is attributed to enhanced mixing rates and reduced residence time for the burned gases before mixing quenches the $\mathrm{NO}_{x}$ reactions; the reaction zone chemistry is insensitive to the source of the diluent. Fuel dilution levels above 20 per cent also eliminate discernible soot formation. Similar results demonstrating the importance of mixing have been shown in fundamental transient jet studies where injecting an inert gas prior to the fuel substantially enhances the turbulent combustion rate [14]. In other fundamental non-premixed combustion studies, $\mathrm{N}_{2}$ is added to methane to reduce fuel concentrations. Laminar co-flow non-premixed flame studies indicate that soot volume fractions are reduced proportionally with the reduction in methane concentration [15]. In a non-premixed opposed-flow diffusion flame, fuel dilution with $\mathrm{N}_{2}$ less than 80 per cent (by volume) has no direct effect on the chemical kinetics of the combustion process [16].

These results suggest that the principal influence of $\mathrm{N}_{2}$ addition is reduced fuel energy density. There is no evidence of direct effects on the reaction kinetics. For a non-premixed transient gaseous jet, such as in a direct-injection engine, a lower fuel energy density will require a longer injection duration to provide an equivalent amount of chemical energy to be released in the combustion. This will increase the total mass injected, significantly increasing the total kinetic energy transfer to the combustion chamber gases. Changing the density of the injected fuel will influence both the penetration and the mixing of the gaseous jet [17]. Previous work studying the effects of injection pressure suggests that changing the gaseous jet's properties can significantly influence the combustion event and emissions [18]. Diluting the fuel should generate similar effects, but without the increase in combustion intensity attributed to the higher fuel-energy injection rate and the associated reduction in combustion duration. The effects of diluting the fuel will also probably influence the local fuel-oxidizer stoichiometry in the reaction zone, affecting both the premixed and the nonpremixed phases of the combustion process. The results with fuel dilution should provide an insightful comparison of the relative importance of mixing and chemical kinetic limitations in the combustion process. 


\section{EXPERIMENTAL DETAILS}

The research facility used in this project is a Cummins ISX series heavy-duty diesel engine modified for single-cylinder operation and adapted to operate on direct injection of natural gas fuelling. The single-cylinder engine, described in Table 1 , has performance and emissions similar to an equivalent natural-gas fuelled multi-cylinder ISX engine [19, 20]. The diesel and gaseous fuel injection processes are controlled using a multi-fuel concentric-needle multi-hole $\mathrm{HPDI}^{\mathrm{TM}}$ injector, produced by Westport Power Inc. Separate electronic solenoids control the timing and duration of the opening of each needle with the pilot diesel fuel actuating both needles independently. The fuel is injected through separate concentric multi-hole nozzles supplied by separate diesel and gaseous fuel supply passages. Details of the injector are provided in Table 1: more information on the injector has been published previously $[2,19]$. Combustion air is supplied from an industrial rotary-screw air compressor fitted with multi-stage water and oil separators. EGR flow is controlled with intake and exhaust pressure controllers and a valve in the EGR loop. This customized air exchange system, shown in Fig. 1, allows the charge conditions to be controlled independently of the engine operating mode and fuel composition.

The engine facility is fully instrumented, with measurements of air and fuel flow (both diesel pilot and natural gas) as well as exhaust composition. The intake air flow is measured, while the EGR rate is determined from the relative concentrations of $\mathrm{CO}_{2}$ in the intake and exhaust streams. The gaseous fuel flow measurement uses a Coriolis-force mass flow sensor, which provides the gaseous mass flowrate independent of the fuel composition. The gaseous fuel composition is determined via gas chromatography. The pilot diesel mass flow is measured using a gravimetric system. Gaseous emissions, including

Table 1 Engine and injector specifications

\begin{tabular}{ll}
\hline Engine & $\begin{array}{c}\text { Cummins ISX single cylinder } \\
\text { four-stroke, four-valve } \\
\text { Fuelling }\end{array}$ \\
& $\begin{array}{c}\text { Direct injection; diesel pilot, } \\
\text { gaseous main fuel }\end{array}$ \\
Displacement (Recylinder) & 2.51 \\
Compression ratio & $17: 1$ \\
Bore & $137 \mathrm{~mm}$ \\
Stroke & $169 \mathrm{~mm}$ \\
Connecting rod length & $261 \mathrm{~mm}$ \\
Injector & Westport Power Inc. dual-fuel \\
& concentric needle \\
Injection control & Separate diesel and natural-gas \\
\multicolumn{1}{c}{ Injector holes } & solenoids \\
Injection angle & pilot, 9 gas \\
\hline
\end{tabular}

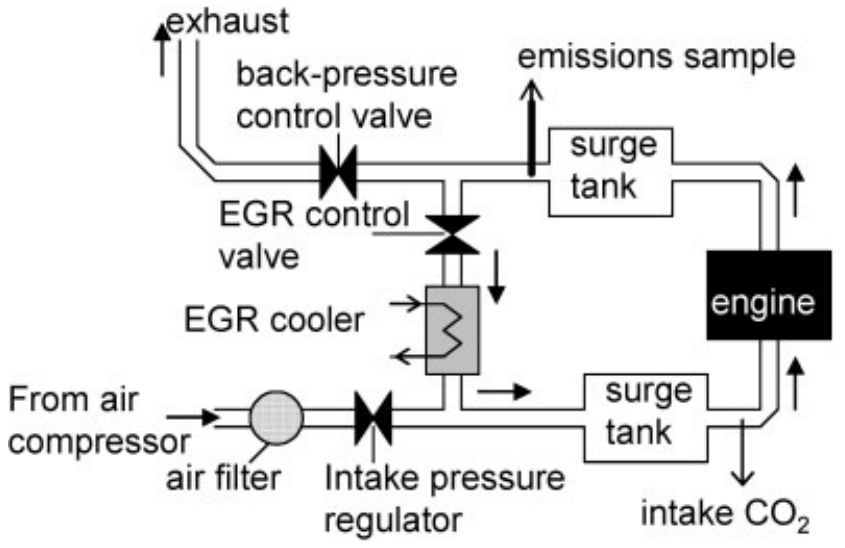

Fig. 1 Experimental system

$\mathrm{CO}, \mathrm{HC}, \mathrm{CO}_{2}$, and $\mathrm{NO}_{x}$, are measured using a raw emissions bench equipped with chemiluminescent $\left(\mathrm{NO}_{x}\right)$, non-dispersive infrared $\left(\mathrm{CO}\right.$ and $\left.\mathrm{CO}_{2}\right)$ and heated flame ionization detectors (HCs). PM emissions are measured using a micro-dilution system, where raw exhaust is diluted (at a volume ratio of 15 to 1 ) by clean dry nitrogen. The total PM mass in the diluted stream is evaluated using a tapered element oscillating microbalance (validated against gravimetric filter measurements [19]). The black-carbon (BC) content of the PM is measured using an aethaelometer, where PM is collected on a quartz filter. The attenuation in the intensity of a monochromatic light shone through the sample indicates the exhaust concentration of light-absorbing $\mathrm{BC}$. Volatile compounds (non-BC PM) can be estimated by subtracting the BC mass emissions from the measured PM emissions. Particle size distributions are measured using a TSI Inc. scanning mobility particle sizer (SMPS), which counts the numbers of particles as a function of mobility diameter between 5 and $150 \mathrm{~nm}$. Further information on the operation and validation of the PM sampling instrumentation has been published previously [19].

The combustion process is monitored using a water-cooled in-cylinder pressure transducer and a $\frac{1}{2}^{\circ}$ crank angle (CA) encoder to identify piston location. This data are used to calculate the gross indicated work per cycle (work done during the compression and power strokes only) and the gross indicated power. The latter is used to normalize the fuel consumption and the emissions measurements. The HRR can also be calculated from the pressure trace [21] according to

$$
\frac{\mathrm{d} Q_{\text {net }}}{\mathrm{d} \theta}=\frac{\gamma}{\gamma-1} p \frac{\mathrm{d} V}{\mathrm{~d} \theta}+\frac{1}{\gamma-1} V \frac{\mathrm{d} p}{\mathrm{~d} \theta}
$$


where $\theta$ is the crank angle, $p$ is the in-cylinder pressure at a given crank angle, $V$ is the cylinder volume at that point, and $\gamma$ is the specific heat ratio (equal to $c_{p} / c_{v}$ - and assumed to be constant). The net HRR represents the rate of energy release from the combustion processes less wall heat transfer and crevice flow losses. The definition of the combustion timing and duration are based on the relative fraction of the total energy released between the start of combustion (identified from the HRR) and the timing of interest, presented as the integral of the heat release (IHR). Combustion timing is defined as the crank angle location at which half of the heat has been released (i.e. 50\% IHR), while the burn duration refers to the total duration of combustion (from 10 to 90 per cent of the IHR). Subdividing the HRR into 'early' (10 to 50 per cent of the IHR) and 'late' ( 50 to 90 per cent of the IHR) stages is also of interest, as it is representative of the relative durations of the premixed and non-premixed combustion phases.

\subsection{Operating conditions}

The engine operating condition used in this work is representative of a high-load steady state cruising mode for a heavy-duty engine. Using an EGR level of 30 per cent achieves relatively low $\mathrm{NO}_{x}$ emissions without degrading the combustion event. Details of the operating condition and fuel blends used in this work are shown in Table 2.

Varying the timing of the combustion provides a range of combustion conditions while maintaining constant charge composition and overall equivalence ratio. For this work, the combustion timing was controlled by varying the timing of the start of the fuel injection process. The timing of the gaseous start of injection (GSOI) was fixed at $1.0 \mathrm{~ms}$ after the end of the diesel injection. The midpoint of the

Table 2 Engine operating conditions and fuel blends

\begin{tabular}{|c|c|c|c|}
\hline Speed (r/min) & \multicolumn{3}{|l|}{1200} \\
\hline Gross indicated power (kW) (\% load) & \multicolumn{3}{|c|}{$35(75 \%)$} \\
\hline $\begin{array}{l}\text { Gross indicated mean effective pressure } \\
\text { (bar) }\end{array}$ & \multicolumn{3}{|l|}{13.5} \\
\hline Gaseous fuel pressure (MPa) & \multicolumn{3}{|l|}{21} \\
\hline EGR (mass \%) & \multicolumn{3}{|l|}{30} \\
\hline Intake oxygen mass fraction & \multicolumn{3}{|l|}{0.19} \\
\hline Combustion timings (50\% IHR) & \multicolumn{3}{|c|}{$0,5,10,15^{\circ}$ ATDC $^{*}$} \\
\hline Fuel $N_{2}$ (vol \%) & 0 & 20 & 40 \\
\hline Fuel $\mathrm{N}_{2}$ (mass \%) & 0 & 30.5 & 53.8 \\
\hline Fuel energy density (MJ/kg) & 45 & 31.3 & 20.8 \\
\hline $\begin{array}{l}\text { Fuel density at standard temperature } \\
\text { and pressure }\left(\mathrm{kg} / \mathrm{m}^{3}\right)\end{array}$ & 0.71 & 0.82 & 0.93 \\
\hline
\end{tabular}

*ATDC, after top dead centre combustion event (50\% IHR) was used as the control variable representing the combustion timing. In this work, combustion timings from the start of the expansion stroke (piston at top dead centre (TDC)) to $15^{\circ}$ after top dead centre (ATDC) were evaluated. Previous work has demonstrated that later timings generate lower $\mathrm{NO}_{x}$ emissions but reduce efficiency and increase combustion instability [5, 21]. For this work, the start-of-injection timing was adjusted for the different fuel blends to maintain the $50 \%$ IHR at the specified value. For all timings, the engine's power output was held constant by varying the mass flowrate of the gaseous fuel (from $5.3 \mathrm{~kg} / \mathrm{h}$ for natural gas to $7.1 \mathrm{~kg} / \mathrm{h}$ at 20 per cent $\mathrm{N}_{2}$ and $10.6 \mathrm{~kg} / \mathrm{h}$ for 40 per cent $\mathrm{N}_{2}$ ). The pilot quantity was fixed at 5 per cent of the total fuel on an energy basis. The pilot diesel and gaseous fuel rail pressures were constant at $21 \mathrm{MPa}$ for all the tests.

\section{RESULTS}

Each test condition was repeated three times to maximize accuracy and to minimize potential bias. The emissions and fuel consumption results are presented as averages of these values. The error bars in the figures indicate the 95 per cent confidence interval around the mean for the data point, based on the randomized repeated measurements. As a result, these uncertainty intervals include variations in the engine operating condition and engine performance as well as instrument variability. The in-cylinder HRRs, and corresponding stability and duration results, are based on 45 consecutive cycles collected at a single test point. These points are representative of the combustion performance for the other replications at the same combustion timing.

\subsection{Combustion process}

Diluting the fuel reduces its energy content (as shown in Table 1) resulting in a longer injection duration for the same power. To maintain constant combustion timing with the diluted fuel, the injection process needs to begin sooner. For both the 20 and the 40 per cent $\mathrm{N}_{2}$ cases the injection starts earlier, as shown in Fig. 2. Simultaneously, the gaseous fuel end of injection (GEOI, also in Fig. 2) is delayed, because of the fuel's lower energy content. At the earlier combustion timings, the slightly lower combustion chamber temperature and pressure with the diluted fuel results in a small 

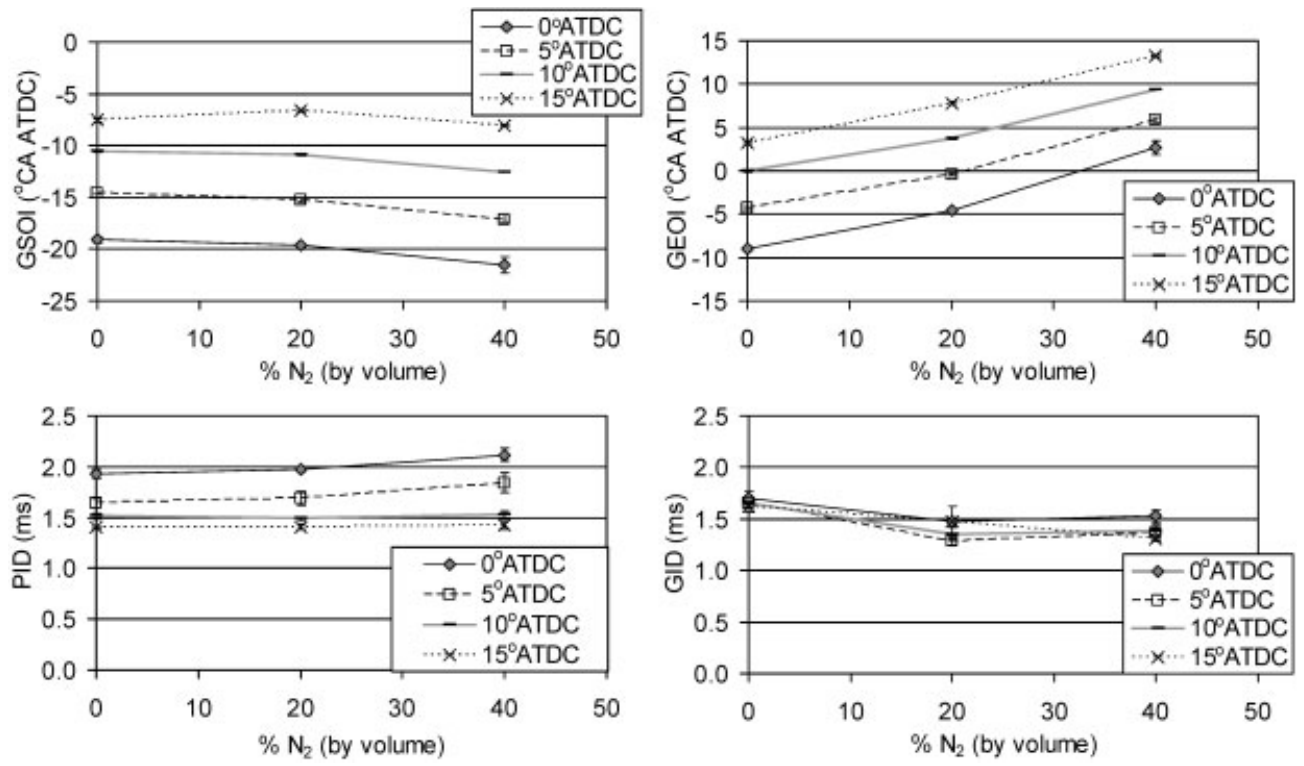

Fig. 2 Gaseous fuel injection timing (GSOI and GEOI), pilot ignition delay (PID), and gaseous fuel ignition delay (GID)

increase in the pilot-fuel ignition delay (PID) time, shown in Fig. 2. Conversely, the ignition delay time of the gaseous fuel, also shown in Fig. 2, is reduced, especially between the natural gas and 20 per cent $\mathrm{N}_{2}$ cases. This is most probably a result of changes in the fuel-air stoichiometry in the gas jet as it approaches the diesel pilot reaction zone. The higher density (and hence higher momentum and greater penetration rate [17]) of the gaseous jet may also bring the ignitable fuel-air cloud closer to the pilot flame at an earlier time. However, the pressure trace provides insufficient information to identify reliably the principal causes of the shorter gaseous fuel ignition delay (GID).

Once the gaseous fuel ignites, $\mathrm{N}_{2}$ dilution reduces the intensity of the initial, partially premixed combustion phase. This arises because less methane has mixed to a combustible level prior to ignition, owing to both the shorter ignition delay time and the lower concentration of methane in the diluted fuel. Once the partially premixed phase is completed, the combustion process is limited primarily by the rate at which the fuel is injected and mixes to a combustible stoichiometry. Both these effects are demonstrated in the HRR plots, shown in Fig. 3 for all four combustion timings. Without nitrogen in the fuel, the partially premixed phase dominates the combustion event at all the timings. With the diluted fuel, the heat release curve is flattened, indicating a more mixing-controlled combustion. The lower intensity of this combustion is primarily a result of the lower flux rate of chemical energy in the fuel injection process. This results in a substantially later end of injection, as demonstrated in Fig. 2. As the combustion timing is retarded, the mixing limitations become more significant. At the earliest timing, the high-fuel-dilution case still has a substantial, partially premixed combustion phase while, at the latest timing, the gaseous combustion is almost completely mixing dominated. This results in a significant reduction in peak HRRs, both with increases in fuel dilution and with later combustion timings.

Although the injection duration is longer and the HRR is lower with $\mathrm{N}_{2}$ in the fuel, the overall combustion duration is not affected, as shown in Fig. 4. The reason is demonstrated by comparing the early and late combustion durations (10 to 50 per cent of the IHR and 50 to 90 per cent of the IHR respectively). At all timings, fuel dilution increases the early combustion duration, owing to the smaller quantity of fuel available to burn in the partially premixed phase. At the later timings, the late-stage combustion duration is substantially reduced. This is a result of the greater kinetic energy transfer to the combustion chamber later in the expansion stroke, resulting in more intense late-cycle turbulence. This leads to more rapid mixing, resulting in a higher HRR late in the cycle (as indicated in the HRR in Fig. 3). At the earliest timing, the late-cycle combustion duration is not significantly reduced; combined with the longer initial combustion event, this results in a net increase in combustion duration. This may be because the end of injection occurs only slightly 

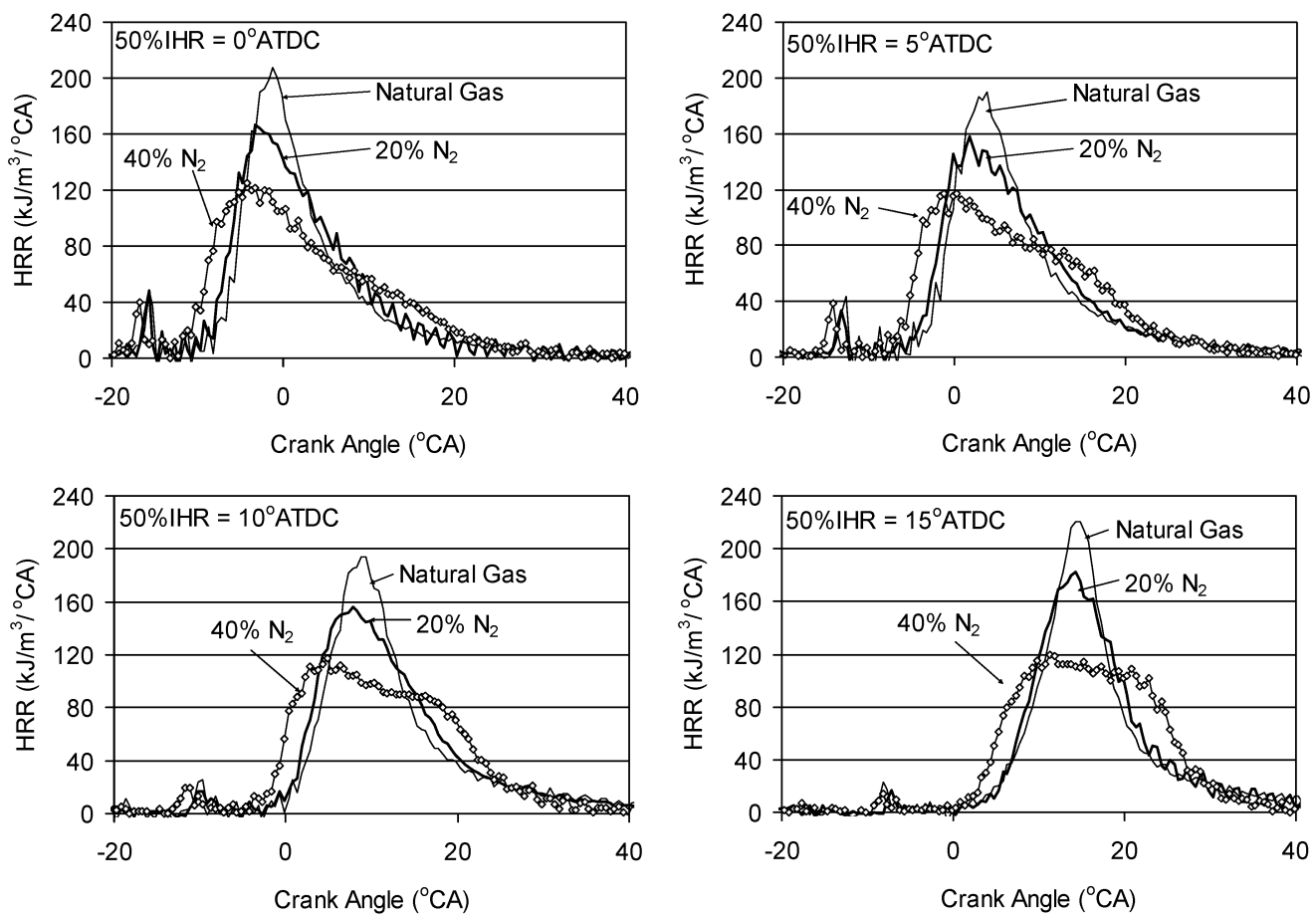

Fig. 3 HRR for all three fuel compositions and all four combustion timings

after top dead centre. At this point, the in-cylinder motion is going to be stronger than later in the expansion stroke, and hence the influence of the kinetic energy from the gaseous jet will be minimized.
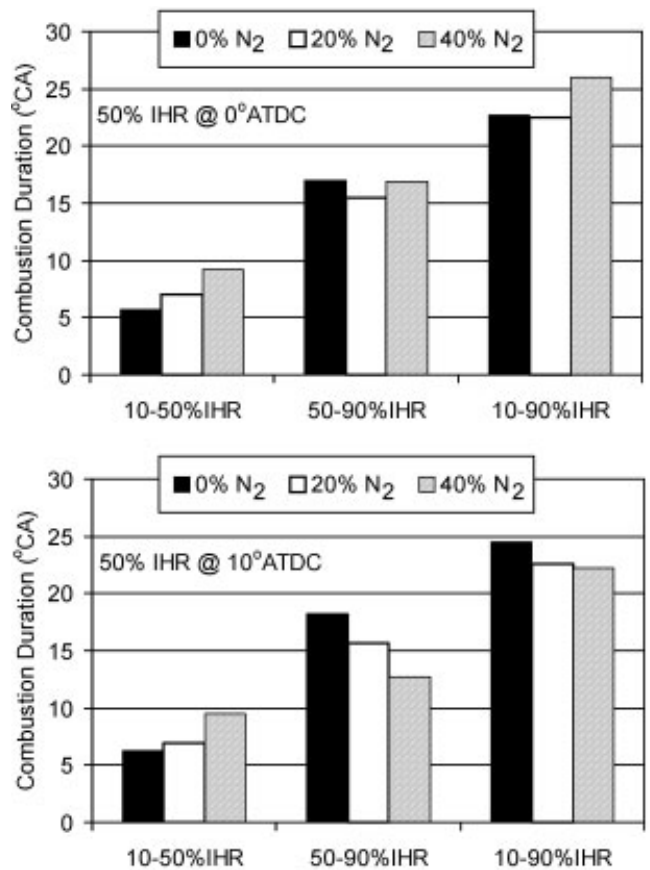

$\mathrm{N}_{2}$ dilution also reduces the variability of the combustion event, as shown in Fig. 5 by the standard deviation of the cycle-to-cycle variation in the combustion duration for the overall, early and late combustion phases (10 to 90 per cent of
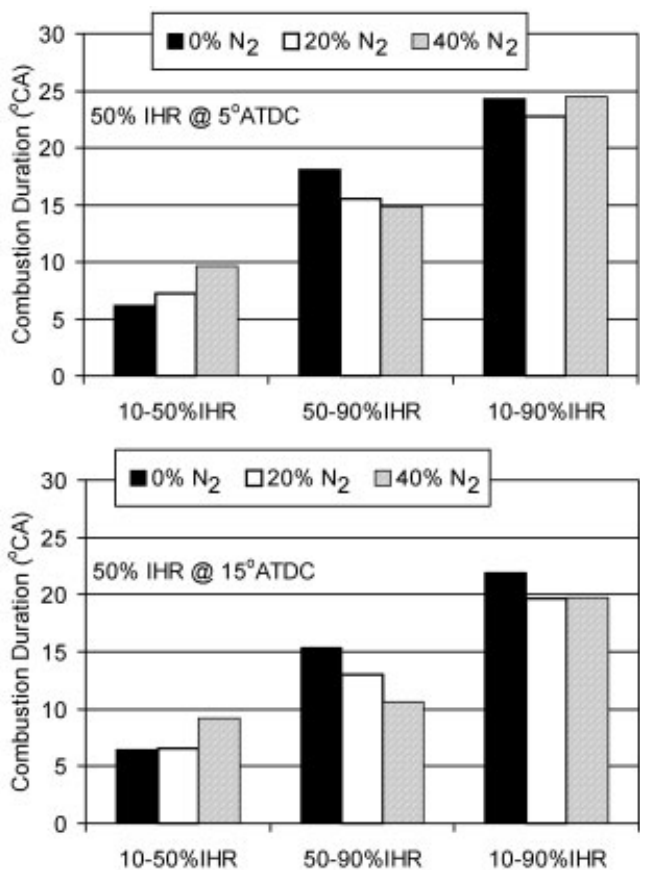

Fig. 4 Early (10 to 50 per cent of the IHR), late (50 to 90 per cent of the IHR) and total (10 to 90 per cent) combustion duration for all three fuel compositions and all four combustion timings 

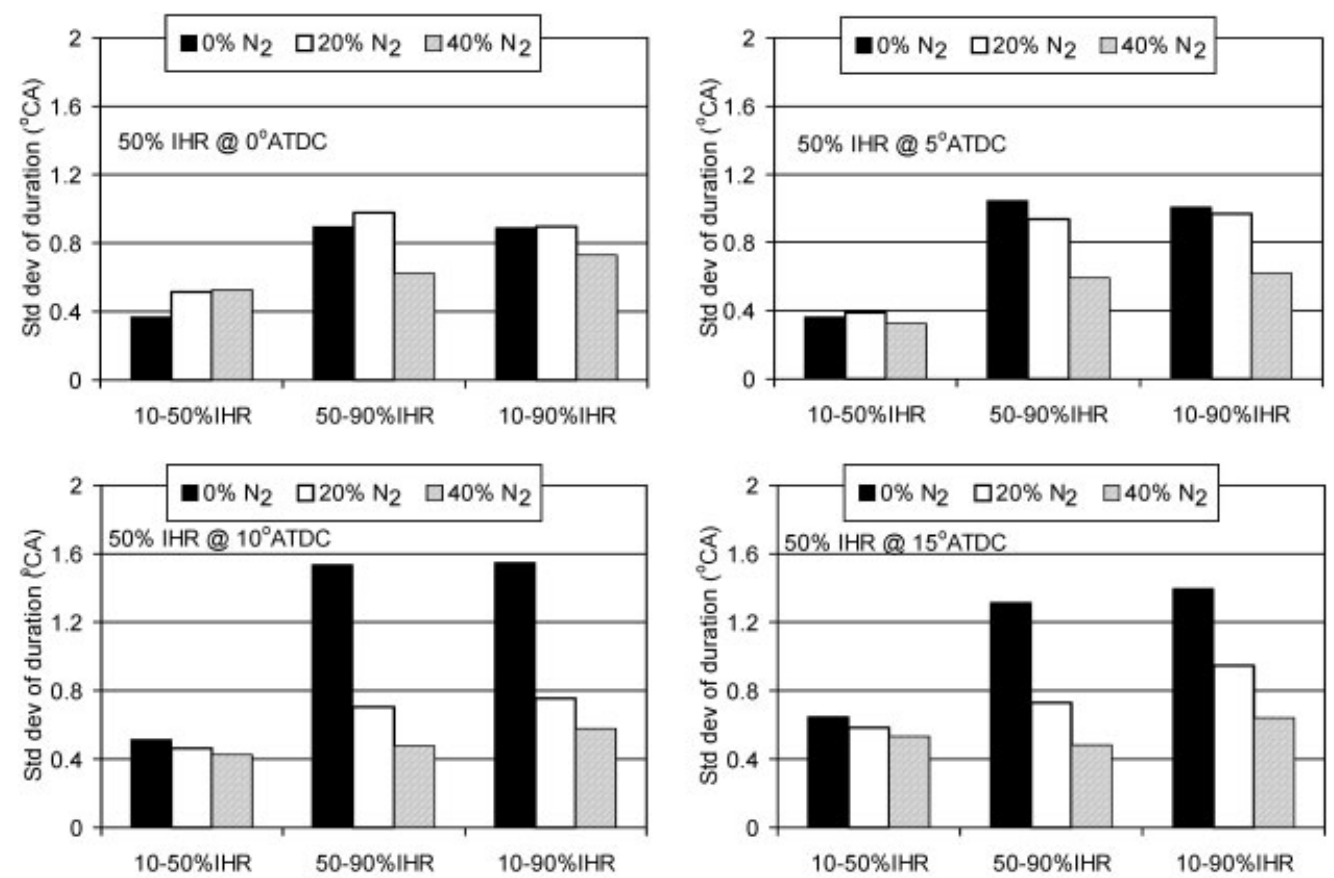

Fig. 5 Stability (represented by standard deviation) of the early (10 to 50 per cent of the IHR), late (50 to 90 per cent of the IHR) and total (10 to 90 per cent) combustion durations for all three fuel compositions and all four combustion timings

the IHR, 10 to 50 per cent of the IHR, and 50 to 90 per cent of the IHR respectively). The reduction in variability is more significant at the later combustion phases; variability in the early combustion is only slightly reduced. This effect is least significant at the earliest combustion timing, where the greater charge motion combines with higher in-cylinder temperatures and pressures during the combustion event to provide greater stability for all the fuel blends. This provides further support for the supposition that the $\mathrm{N}_{2}$ addition is significantly enhancing the late-cycle mixing for the later combustion timings, resulting in more rapid and repeatable combustion.

The fact that nitrogen addition enhances the stability of the combustion event results in a small improvement in the fuel conversion efficiency. This is represented in Fig. 6 by the gross indicated specific fuel consumption (GISFC), in terms of the energy content of the fuel based on an equivalent mass of diesel. The fact that only the earliest timing case does not show a reduction in fuel consumption indicates that the combustion stability improvements, which are much less at this condition, are one of the primary contributors to the improved efficiency. As this parameter relates to the combustion efficiency only, it does not account for the increased work required to compress the diluted fuel to the injection pressure.

\subsection{Emissions}

Dilution of the gaseous fuel with nitrogen has a substantial effect on both gaseous and PM emissions. These impacts are attributable, in general, to the effects of the $\mathrm{N}_{2}$ on the fuel-air stoichiometry and on the charge motion due to the increased mass and density of the gaseous jet. Previous studies suggest that $\mathrm{N}_{2}$ in the fuel plays little direct role in the reaction kinetics [13].

The effect of $\mathrm{N}_{2}$ dilution on the emissions of $\mathrm{NO}_{x}$, $\mathrm{CO}$ and $\mathrm{HC}$ are shown in Fig. 6. At all the combustion timings, the $\mathrm{NO}_{x}$ emissions increase slightly with 20 per cent $\mathrm{N}_{2}$ dilution, but drop significantly at 40 per cent $\mathrm{N}_{2}$. These reductions most probably arise because the lower-intensity combustion leads to lower combustion temperatures. However, the reductions are not nearly as significant as suggested by the reduction in the adiabatic flame temperature under stoichiometric conditions with $\mathrm{N}_{2}$ dilution. According to previous results, the reduction in flame temperature (about $80 \mathrm{~K}$ ) with 40 per cent $\mathrm{N}_{2}$ dilution should reduce $\mathrm{NO}_{x}$ emissions by approximately 40 per cent $[\mathbf{5}, \mathbf{1 9}]$, twice the observed reduction. Changes in the stoichiometry in the reaction zone may be leading to variations in actual combustion temperature that are not predicted using the calculated adiabatic (stoichiometric) flame temperature. Changes in mixing rates could also 

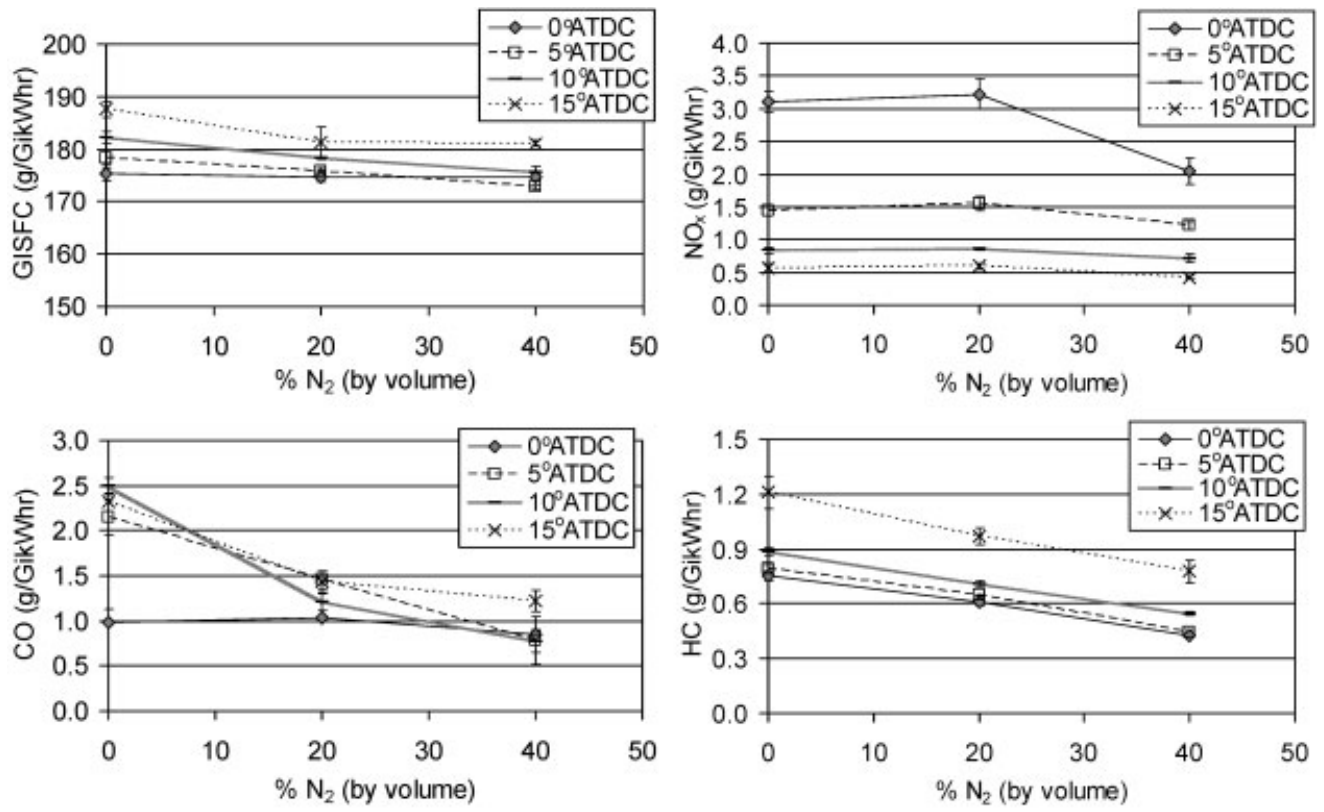

Fig. 6 GISFC and emissions of $\mathrm{NO}_{x}, \mathrm{HCs}$, and $\mathrm{CO}$ as functions of the fuel dilution and combustion timing, normalized by gross indicated power (GikWhr, gross indicated kilowatt hour)

result in longer residence times for the burned gases at high temperatures, allowing the thermal NO reactions to proceed closer to equilibrium. At this EGR level (30 per cent) it is possible that the prompt NO formation mechanism, which involves a reaction between $\mathrm{N}_{2}$ and $\mathrm{CH}$ radicals on the fuel-rich side of the reaction zone [22], could be making a significant contribution to the total $\mathrm{NO}_{x}$ formation. It is likely that this mechanism could be significantly enhanced with the presence of significant quantities of $\mathrm{N}_{2}$ on the fuel side of the reaction zone.

HC emissions, which are more than 95 per cent unburned methane, decrease linearly with increasing $\mathrm{N}_{2}$ dilution. These reductions are consistent in magnitude, at $160 \mathrm{mg} / \mathrm{kWh}$ per 20 per cent increment in $\mathrm{N}_{2}$ concentration in the fuel, for all combustion timings. This reduction is equal to 20 per cent of the unburned fuel emitted in the lowestemissions case. This suggests that the HC emissions are related to a fixed volume of unburned fuel. This may be a result of the fuel retained in the injector sac and nozzle passages at the end of the injection process, which then vents into the combustion chamber during the expansion stroke as the cylinder pressure falls. It may also be due to early-injected fuel, which mixes beyond the combustible limit before ignition occurs. The fact that the earliest timing responds in an identical manner to the later timings suggests that the primary source of HCs is not related to combustion stability. It further suggests that the mechanisms for HC production are significantly different from those of $\mathrm{CO}$ and PM, whose response to fuel dilution differs significantly between the earliest and the later timings.

The CO emissions are also significantly reduced with the addition of $\mathrm{N}_{2}$ to the fuel at most combustion timings. At the earliest timing, conversely, $\mathrm{CO}$ is not significantly reduced. These results compare directly with the GISFC improvements and enhanced latecycle combustion stability at the later timings, effects that also are not apparent at the earliest combustion timing. The fact that the combustion is significantly more stable with $\mathrm{N}_{2}$ is probably one of the principal causes of this reduction, since $\mathrm{CO}$ emissions are often a result of incomplete combustion, especially late in the combustion cycle as a result of bulk quenching of the reactants. Furthermore, these incompletecombustion processes are also often associated with emissions of PM.

\subsection{Particulate emissions}

PM emissions are substantially reduced by $\mathrm{N}_{2}$ dilution at moderate timings, as shown in Fig. 7. At the latest timing, $\mathrm{N}_{2}$ dilution has no significant effect on the total PM mass emissions, while PM emissions are increased at the earliest timing. The effect at late timing may be a result of the very low emissions levels at this operating condition, which is 

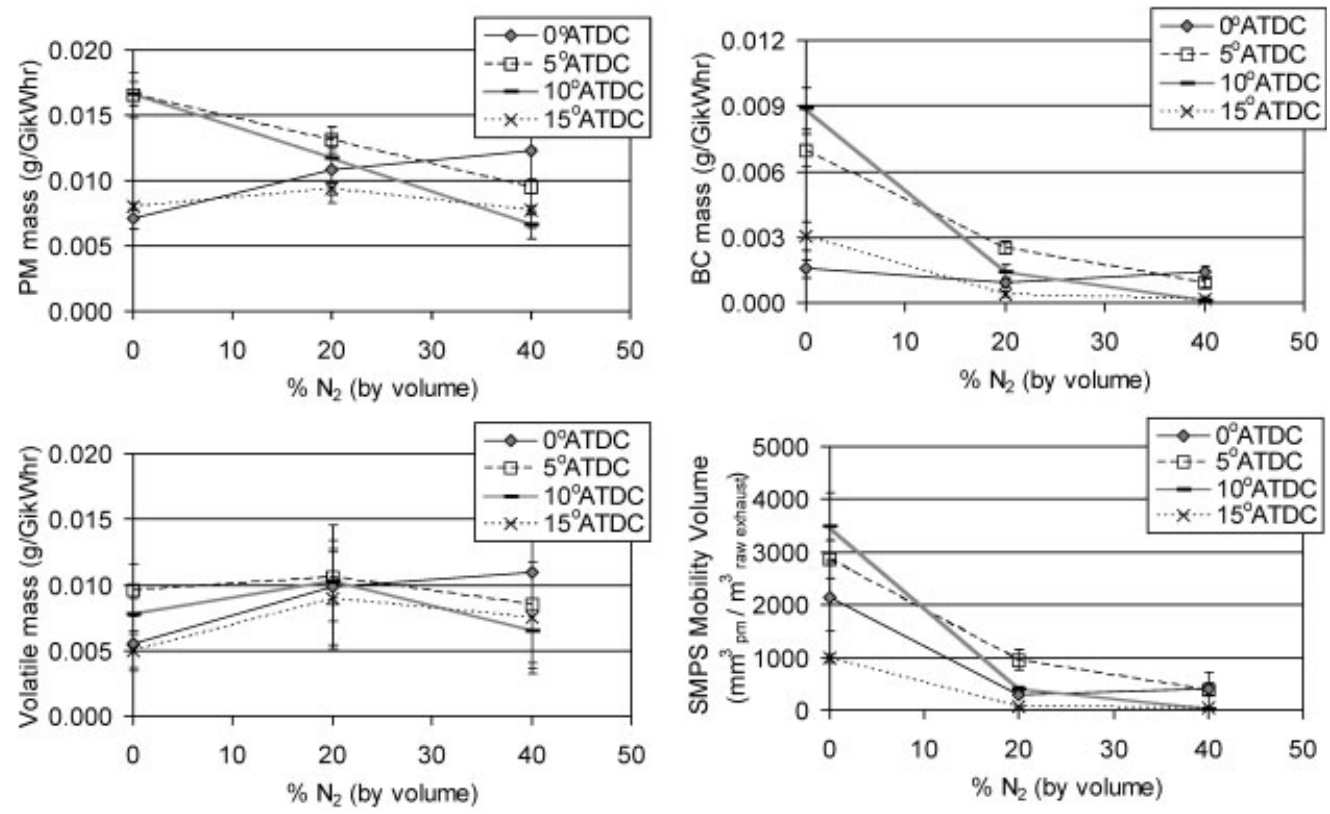

Fig. 7 Total PM mass, BC mass, and volatile PM mass normalized by gross indicated power, and particle mobility volume concentration measured by the SMPS, as functions of the fuel dilution and combustion timing (GikWhr, gross indicated kilowatt hour)

approaching the lowest PM levels recorded for the engine; this baseline value is normally attributed to volatile emissions. The increase in PM with $\mathrm{N}_{2}$ addition at the earliest timing provides further evidence that this condition is behaving in a fundamentally different manner from the other combustion timings. This may be a result of reduced mixing around TDC, but it may also be associated with the increased gaseous jet penetration with $\mathrm{N}_{2}$ addition, resulting in impingement of the reaction zone on the piston bowl. This early quenching of the combustion event could lead to increased PM emissions through reduced oxidation.

Figure 7 also shows the BC content of the PM. $\mathrm{N}_{2}$ dilution greatly reduces $\mathrm{BC}$ emissions at the later timings; this agrees with previous studies of lowpressure non-premixed combustion systems which found that fuel dilution eliminates in-flame BC formation [13]. Whether similar effects are occurring in this high-pressure combustion system, or whether the reduction is due to enhanced oxidation late in the combustion process, is a subject of ongoing research. At the earliest timing, there is no significant reduction in $\mathrm{BC}$ emissions. As discussed previously, this may be a result of reduced mixing or early reaction quenching due to gaseous fuel jet impingement.

As the BC emissions are reduced with fuel dilution, condensed volatile emissions (Fig. 7) become the principal component of the PM emissions. These results show substantial uncertainty, as they are calculated by subtracting the $\mathrm{BC}$ emissions from the total PM mass, both of which suffer from relatively high uncertainties. Despite this, the results demonstrate that there is no substantial or consistent change in volatile emissions with fuel dilution. These volatile species may originate from unburned diesel, lubricating oil, or even natural-gas-derived soot precursors which have not formed solid carbon. The volatiles then either will condense on to existing particles in the exhaust stream, or will nucleate to form new particles. These results suggest that the bulk of the observed reduction in PM emissions can be attributed to reductions in $\mathrm{BC}$ emissions.

The BC emissions show a strong correlation with the mobility volume of the particles measured using the SMPS, also shown in Fig. 7. This measure uses the particle size distribution and an approximation of the particle shape to estimate the volume of particulate matter in the $5-150 \mathrm{~nm}$ size range. The significant reduction in particle volume with nitrogen addition at most timings demonstrates the importance of latecycle mixing on either inhibiting PM formation or on enhancing oxidation of the existing PM. The close correlation between the volume of particles less than $150 \mathrm{~nm}$ in diameter and the $\mathrm{BC}$ indicates that the principal source of this particulate is BC.

Further insight regarding the PM is provided by the particle size distributions, shown in Fig. 8. These plots represent the concentration of particles (in number of particles per unit volume of raw exhaust) 

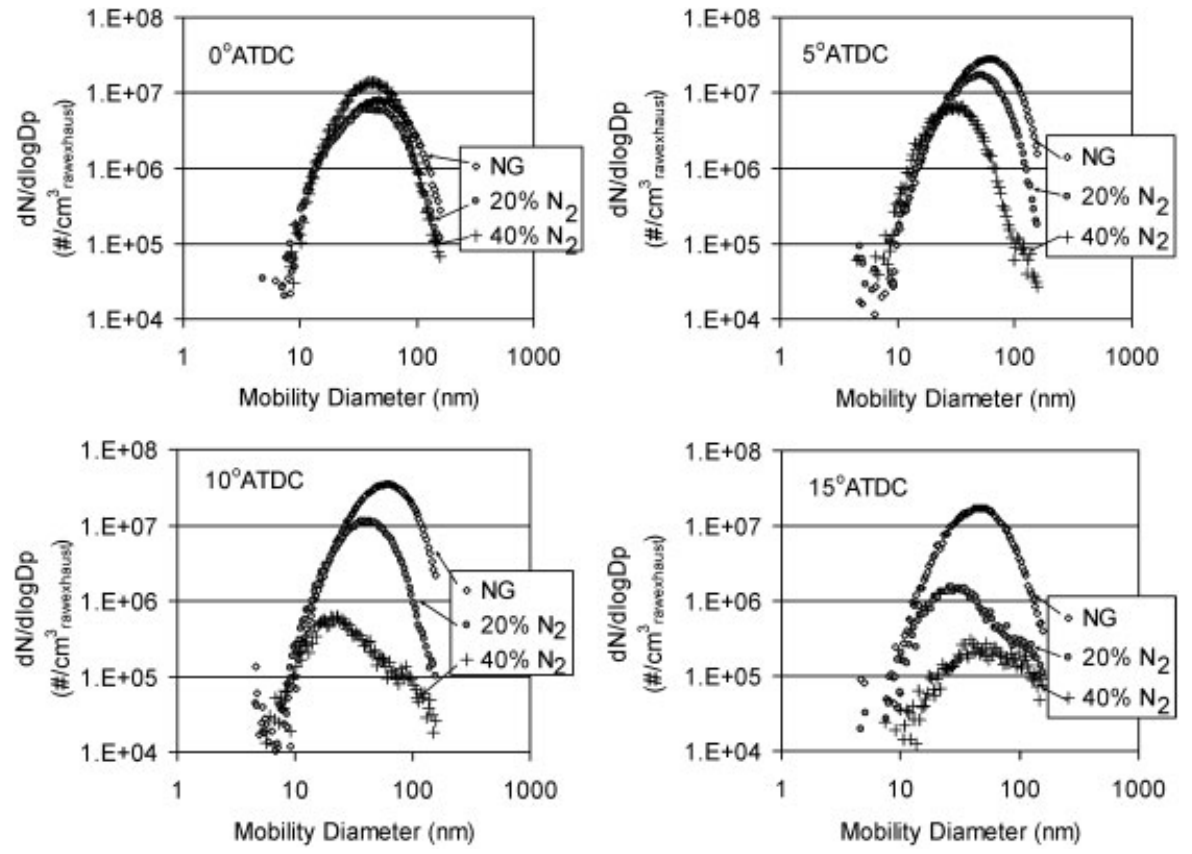

Fig. 8 Particle size distributions as a function of the fuel dilution and combustion timing (NG, natural gas)

of a given mobility size range in the exhaust stream. Integrating these distributions provides the total number of particles: however, these results are not shown here, as the trends are similar to the particle volume results shown in Fig. 7 and the results do not provide more insight than is provided from the size distributions shown in Fig. 8. At the later timings, the number of particles of all size ranges is significantly reduced with fuel dilution. Not only is the total number of particles reduced, but also the diameter at which the peak number of particles occur is substantially smaller. This is consistent with higher fuel-oxidizer mixing rates, which result in less time for particulate inception and growth to occur under fuel-rich conditions, as well as enhancing post-formation oxidation. At the earliest timing, the number of particles increases with increasing fuel dilution; this is consistent with the increase in mass shown in Fig. 7. This may be a result of changes in the fuel-air stoichiometry, resulting in lower oxygen concentrations being available to oxidize the nanoparticles or their precursors during the combustion event.

The combined measurements of PM indicate that the engine-out volatile PM emissions are significant and become more significant as BC emissions are reduced. These readings suggest that, even with near-zero BC emissions, PM total mass is approaching the levels of the most stringent future emissions standards. While in-cylinder reduction of these emissions, together with further $\mathrm{BC}$ reductions, is desirable, volatiles can be removed from the exhaust steam more easily than can BC. Many diesel and natural-gas engines are already equipped with oxidation catalysts to control $\mathrm{HC}$ and $\mathrm{CO}$ emissions; these are also generally effective at removing volatile species which could otherwise condense post-exhaust to form PM.

\section{DISCUSSION}

One of the main impacts of this study is in improving fundamental understanding of pilotignited direct-injected natural-gas combustion systems. Increasing the mass of the gaseous jet significantly increases late-cycle turbulence without significantly affecting the chemical kinetics. This late-cycle turbulence enhances fuel burn-up, resulting in lower emissions of unburned fuel and other combustion by-products, including CO and PM. This effect is not observed at the earliest combustion timing, where half of the combustion occurs prior to the piston reaching TDC. Earlier in the cycle, the charge motion induced by the air ingestion and compression processes will be highest. As a result, the turbulence caused by the gaseous jet may not have as significant an impact at improving mixing. Alternatively, gaseous jet impingement on the piston surface may be prematurely extinguishing $\mathrm{CO}$ and 
PM oxidation processes. The fact that the HC emissions follow the same trend at all operating conditions further reinforces the presumption that these are associated with a fuel-volume effect. This earliest timing, in which half the combustion has completed prior to TDC, is not a timing typically used for direct-injection compression ignition engines. Over a range of more typical combustion timings, the addition of diluent to the fuel has a significant effect at reducing pollutant emissions.

Diluting the fuel increases the in-cylinder turbulence through the gaseous jet's higher kinetic energy, resulting in a substantial improvement in the combustion event. Qualitatively similar improvements in mixing can be achieved through increases in injection pressure [18]. As more of the fuel is injected and mixes prior to ignition, higher injection pressures result in a substantial increase in the premixed component of the combustion event. This leads to higher combustion temperatures and greater $\mathrm{NO}_{x}$ formation. At some timings, the greater premixing also results in higher $\mathrm{HC}$ and $\mathrm{CO}$ emissions due to over-leaning of the early injected fuel. The achievable benefits are also limited by physical restrictions on the gaseous fuel system pressure.

The significant reductions in emissions with fuel dilution suggest that there may be some commercial applicability for this technique. In transportation applications, the need to supply and transport highly diluted fuel either as a liquid or as a compressed gas will tend to reduce its applicability. An auxiliary gaseous fuel tank, filled with a diluent, could be used to provide diluted fuel for engine operation under conditions where emissions might otherwise exceed legislated levels. Whether the benefits would be worth the increase in fuel system complexity needs to be determined. A more probable application is in stationary uses, where diluent could be added to the fuel supply stream. The concentration of these diluents could be used as a tool to counteract higher levels of other more polluting species in the fuel, allowing more complete usage of the fuel stock with fewer processing requirements. The principal cost for stationary applications would be the extra work required to compress the diluted fuel mixture. This cost would be offset by the improvement in combustion efficiency combined with reduced exhaust treatment requirements that could be achieved with fuel dilution.

\section{CONCLUSIONS}

The principal impacts of diluting a gaseous fuel with nitrogen are: (a) a reduction in the initial combustion intensity and the peak HRR due to lower chemical energy available in the partially premixed charge following ignition. However, the late-phase combustion process is enhanced through more rapid mixing and combustion, primarily attributed to the higher gaseous jet kinetic energy;

(b) a reduction in combustion instability. This is due primarily to enhanced late-cycle combustion and a more consistent premixed combustion phase;

(c) a substantial reduction in both the mass of total PM and the mass of BC (soot) at most timings. High levels of $\mathrm{N}_{2}$ dilution can effectively eliminate $\mathrm{BC}$ emissions, although condensed volatile emissions are not significantly influenced;

(d) a reduction in fuel emissions by a constant amount for a given quantity of fuel. This suggests that sources of $\mathrm{HC}$ emissions at these operating conditions are volume related, including fuel retained in the injector nozzle and gas plenum or over-leaning of gaseous fuel injected early in the injection process. That the $\mathrm{HC}$ emissions are not primarily due to incomplete combustion reactions is reinforced by the significant differences in its response to timing and fuel dilution compared with $\mathrm{CO}$ and PM emissions, as these are typically caused by incomplete combustion;

(e) a slight reduction in emissions of $\mathrm{NO}_{x}$. This finding suggests either that the combustion temperature is not being reduced as much as anticipated or that the residence time in the post-flame gases is greater, allowing the NOforming chemical reactions to approach equilibrium more closely;

(f) that these effects are not as significant at the earliest combustion timing. The experimental results suggest that, for very early timings, either mixing is not a limiting factor to the combustion event or the combustion event is being restricted by impingement on the piston. Enhancing this mixing through higher turbulence has no significant impact on the combustion event or emissions, suggesting that, at this timing, chemical kinetics are dominating the combustion event. Over the range of timings typically encountered in heavy-duty engine operation, mixing enhancement has a significant effect on reducing emissions and improving combustion stability. 


\section{ACKNOWLEDGEMENTS}

The authors gratefully acknowledge financial and technical support from Westport Power Inc. and financial support from the Natural Sciences and Engineering Research Council of Canada. The staff at the University of British Columbia, and in particular H. Jones and R. Parry, provided invaluable assistance in conducting this work.

\section{REFERENCES}

1 Richards, G. A., McMillian, M. M., Gemmen, R. S., Rogers, W. A., and Cully, S. R. Issues for lowemission, fuel-flexible power systems. Prog. Energy Combust. Sci., 2001, 27, 141-169.

2 Harrington, J., Munshi, S., Nedelcu, C., Ouellette, P., Thompson, J., and Whitfield, S. Direct injection of natural gas in a heavy-duty diesel engine. SAE technical paper 2002-01-1630, 2002.

3 California Air Resources Board, Executive Order A343-0003, available from www.arb.ca.gov/msprog/ onroad/cert/mdehdehdv/2006/westport_hhdd_a3430003_ 14d9_1d2-0d02_cngplusdiesel.pdf, accessed 27 March 2007.

4 McTaggart-Cowan, G. P., Reynolds, C. C. O., and Bushe, W. K. Natural gas fuelling for heavy-duty on-road use: current trends and future direction. Int. J. Environmental Stud., 2006, 63(4), 421-440.

5 Hill, P. G. and McTaggart-Cowan, G. P. Nitrogen oxide production in a diesel engine fuelled with natural gas. SAE technical paper 2005-01-1727, 2005.

6 Jones, H. L., McTaggart-Cowan, G. P., Rogak, S. N., Bushe, W. K., Munshi, S. R., and Buchholz, B. A. Source Apportionment of particulate matter from a direct injection pilot-ignited natural gas fuelled heavy duty DI engine. SAE technical paper 2005-01-2149, 2005.

7 Ladommatos, N., Abdelahlim, S., and Zhao, $H$. The effects of exhaust gas recirculation on diesel combustion and emissions. Int. J. Engine Res., 2000, 1(1), 107-126.

8 Yun, H. and Reitz, R. D. Combustion optimization in the low-temperature diesel combustion regime. Int. J. Engine Res., 2005, 6(5), 513-525.

9 Zhao, H., Peng, Z., and Ladommatos, N. Understanding of controlled autoignition combustion in a four-stroke gasoline engine. Proc. Instn Mech. Engrs, Part D: J. Automobile Engineering, 2001, 215, 1297-1309.

10 Aiyoshizawa, E., Hasegawa, M., Kawashima, J., and Muranaka, S. Combustion characteristics of a small DI diesel engine. JSAE Rev., 2000, 21, 241-243.

11 Nellen, C. and Boulouchos, K. Natural gas engines for cogeneration: highest efficiency and near-zero emissions through turbocharging, EGR and 3-way catalytic converter. SAE technical paper 2000-012825, 2000.
12 Crookes, R. J. Comparative bio-fuel performance in internal combustion engines. Biomass Bioenergy, 2006, 30, 461-468.

13 Feese, J. J. and Turns, S. R. Nitric oxide emissions from laminar diffusion flames: effects of air-side versus fuel-side diluent addition. Combust. Flame, 1998, 113, 66-78.

14 Kido, H., Hashimoto, J., Barat, D., Nishigaki, M., and Okamoto, H. Effect of inert gas on turbulent burning velocities. JSME Int. J., Ser. B, 2001, 44(1), 119-125.

15 Gulder, O. L. Effects of oxygen on soot formation in methane, propane, and $n$-butane diffusion flames. Combust. Flame, 1995, 101, 302-310.

16 Fotache, C. G., Kreutz, T. G., and Law, C. K. Ignition of counterflowing methane versus heater air under reduced and elevated pressures. Combust. Flame, 1997, 108, 442-470.

17 Hill, P. G. and Ouellette, P. Transient turbulent gaseous fuel jets for diesel engines. Trans. ASME, J. Fluids Engng, 1999, 121, 93-101.

18 McTaggart-Cowan, G. P., Jones, H. L., Rogak, S. N., Bushe, W. K., Hill, P. G., and Munshi, S. R. The effects of high pressure injection on a compression ignition, direct injection of natural gas engine. Trans. ASME, J. Engng Gas Turbines Power, 2007, 129, 579-588.

19 McTaggart-Cowan, G. P., Bushe, W. K., Hill, P. G., and Munshi, S. R. A supercharged heavy-duty diesel single-cylinder research engine for highpressure direct injection of natural gas. Int. J. Engine Res., 2004, 4(4), 315-330.

20 McTaggart-Cowan, G. P. Pollutant formation in a gaseous-fuelled, direct injection engine. $\mathrm{PhD}$ Thesis, University of British Columbia, 2006.

21 Heywood, J. B. Internal combustion engine fundamentals, 1988 (McGraw-Hill, New York).

22 Warnatz, J., Maas, U., and Dibble, R. W. Combustion - physical and chemical fundamentals, modeling and simulation, experiments, pollutant formation, 2nd edition, 1998 (Springer-Verlag, Berlin).

\section{APPENDIX}

\section{Notation}

$50 \%$ IHR midpoint of integrated heat release

ATDC after top dead centre

BC black carbon

CA crank angle

EGR exhaust gas recirculation

GEOI gaseous fuel end of injection

GID gaseous fuel ignition delay

GSOI gaseous fuel start of injection

GISFC gross indicated specific fuel consumption

HC hydrocarbon 
HRR

IHR

heat release rate

integrated heat release

PID

nitrogen oxides ( $\mathrm{NO}$ and $\mathrm{NO}_{2}$ )
PM

SMPS pilot ignition delay

(fine) particulate matter

scanning mobility particle sizer 